\title{
O viver de idosos após o acidente vascular cerebral
}

The living of elderly people after stroke

La vida de ancianos después del accidente cerebrovascular

\section{Eglon Pauli', Marinês Tambara Leite ${ }^{\mathrm{II}}$, Larissa Bornholdt ${ }^{\mathrm{III}}$, Leila Mariza Hildebrandt ${ }^{\mathrm{IV}}$ Sandra da Silva Kinalski ${ }^{v}$, Margrid Beuter ${ }^{\mathrm{VI}}$}

\begin{abstract}
Resumo: Objetivo: compreender o viver de idosos após a ocorrência de um Acidente Vascular Cerebral (AVC). Método: investigação qualitativa e descritiva. Dados coletados entre janeiro e março de 2018 em três Estratégias de Saúde da Família (ESF), por meio de entrevista semiestruturada com idosos, vítimas de AVC, cujas informações foram analisadas conforme análise temática. Resultados: os dados permitiram construir três categorias: modificações funcionais e sociais na vida de idosos após a ocorrência do AVC; o (des) cuidado após o AVC no entendimento da pessoa idosa; e perspectivas de futuro da pessoa idosa após a ocorrência do AVC. A assistência imediata e resolutiva na instituição hospitalar, o acompanhamento da ESF e o envolvimento familiar são fundamentais para a reabilitação da pessoa idosa. Considerações finais: os resultados permitiram compreender o viver de idosos, que apresentaram mudanças em seu cotidiano após a ocorrência do AVC, com diferentes graus de comprometimentos físicos e psíquicos.
\end{abstract}

Descritores: Enfermagem; Acidente vascular cerebral; Idoso; Estratégia saúde da família

Abstract: Objective: to understand the living of elderly people after the occurrence of a Stroke (FAST). Method: qualitative and descriptive research. Data collected between January and March 2018 in three Family Health Strategies (FHS), through semi-structured interviews with elderly people, stroke victims, whose information was analyzed according to thematic analysis. Results: the data allowed the construction of three categories: the functional and social changes in the lives of elderly people after the occurrence of stroke; the (lack of) care after stroke in the understanding of the elderly person; and the future perspectives of the elderly person after stroke. Immediate and resolutive assistance in the hospital, the follow-up at FHS and the family involvement are essential

\footnotetext{
${ }^{\text {I }}$ Enfermeiro, Residente do Programa de Residência Multiprofissional em cardiologia do Hospital de Clínicas. Passo Fundo, RS, Brasil. E-mail: paulieglon@hotmail.com. ORCID: 0000-0001-6724-5756

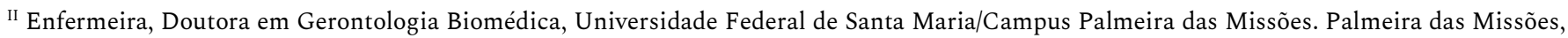
RS, Brasil. E-mail: tambaraleite@yahoo.com.br. ORCID: 0000-0003-3280-337X

III Enfermeira, Graduada. Hospital São Vicente de Paulo. Passo Fundo, RS, Brasil. E-mail: lari.derru@hotmail.com. ORCID: 0000-0003-1278-4677

${ }^{\text {IV }}$ Enfermeira, Doutora em Ciências. Universidade Federal de Santa Maria/Campus Palmeira das Missões. Palmeira das Missões, RS, Brasil. Email: leilahildebrandt@yahoo.com.br. ORCID: 0000-0003-0504-6166

v Enfermeira, Mestre em Atenção Primária em Saúde. Universidade Regional Integrada/Campus Santo Ângelo. Ijuí, RS, Brasil. E-mail: sandrakinalski@yahoo.com.br. ORCID: 0000-0002-4841-2288

VI Enfermeira, Doutora em Ciências, Universidade Federal de Santa Maria. Santa Maria, RS, Brasil. E-mail: margridbeuter@gmail.com. ORCID: 0000-0002-3179-9842
} 
for the rehabilitation of the elderly person. Final considerations: the results allowed us to understand the lives of the elderly patients, who showed changes in their daily lives after stroke, with different degrees of physical and psychological impairment.

Descriptors: Nursing; Stroke; Elderly; Family Health Strategy

Resumen: Objetivo: comprender la vida de ancianos después de la ocurrencia de un accidente cerebrovascular. Método: investigación cualitativa y descriptiva. Datos recopilados entre enero y marzo de 2018 en tres Estrategias de Salud Familiar (ESF), mediante entrevistas semiestructuradas con ancianos, víctimas de accidente cerebrovascular, cuya información se analizó de acuerdo con el análisis temático. Resultados: los datos permitieron la construcción de tres categorías: los cambios funcionales y sociales en la vida de los ancianos después del accidente cerebrovascular; el (des) cuidado después del accidente cerebrovascular en la comprensión del anciano; y perspectivas futuras del anciano después del accidente cerebrovascular. La atención inmediata y resolutiva en el hospital, el monitoreo de la ESF y la participación familiar son esenciales para la rehabilitación del anciano. Consideraciones finales: los resultados permitieron comprender la vida de los ancianos evaluados, que mostraron cambios en su vida diaria después del accidente cerebrovascular, con diferentes grados de discapacidad física y psicológica.

Descriptores: Enfermería; Accidente Cerebrovascular; Anciano; Estrategia de Salud Familiar.

\section{Introdução}

O Acidente Vascular Cerebral (AVC) é uma lesão neurológica causada pela diminuição ou interrupção do fluxo sanguíneo no cérebro. Está dividido em dois grupos, isquêmico e hemorrágico. O isquêmico apresenta maior taxa de incidência, com $87 \%$ dos casos, e caracteriza-se pela obstrução de um vaso, resultando em necrose do tecido cerebral. O hemorrágico, $13 \%$ dos casos, evidencia-se pela ruptura de um vaso no encéfalo, com extravasamento de sangue para o espaço intraparenquimatoso ou subaracnoideo. ${ }^{1-2}$ Constitui-se em uma doença com início agudo dos sintomas, rápida perda da função neurológica, podendo apresentar alterações como paresia (diminuição da força motora) e coma. ${ }^{1}$

As doenças cerebrovasculares possuem maior incidência em indivíduos com idade igual ou superior a 65 anos, isto é, a população idosa é mais vulnerável ao AVC do que qualquer outra faixa etária. ${ }^{1}$ Dados mostram que, em 2013, 1,5\% dos indivíduos, com 18 anos ou mais de idade, teve diagnóstico de AVC, constituindo uma população de 2,2 milhões de pessoas. ${ }^{3}$ De acordo com o manual das Diretrizes de Atenção à Reabilitação da Pessoa com AVC de 2013, a 
3 | Pauli E, Leite MT, Bornholdt L, Hildebrandt LM, Kinalski, SS, Beuter M.

incidência anual desta morbidade é de 108 casos para cada 100 mil habitantes, com índice de 18,5\% como taxa de fatalidade, 30 dias após sua ocorrência, e de 30,9\% após 12 meses, em que as chances de recorrência após um episódio são de $15,9 \%{ }^{3}$

Estudo mostra aumento do número de casos de pessoas idosas acometidas por AVC, indicando que esta é a segunda causa de morte no mundo, resulta em sequelas que podem afetar o idoso física e psiquicamente, dependendo da área lesada, e, muitas vezes, são as responsáveis pela exclusão social do mesmo. Além disso, os indivíduos que vivenciaram um ou mais episódio desta morbidade tem maior risco de morte na fase aguda, probabilidade de reincidências e de incapacidades que podem comprometer o seu cotidiano em longo prazo. ${ }^{1}$

A elevada incidência, alto ônus social e aumento considerável da incapacidade relacionada ao AVC em idosos nas últimas décadas, têm implicado em um desafio para a sociedade. A reabilitação estruturada e multidisciplinar reduz a incapacidade relacionada ao AVC, tanto em sobreviventes mais velhos quanto em jovens, independentemente de sua gravidade. Além disso, há evidências crescentes para apoiar a eficácia clínica de intervenções específicas de reabilitação aos indivíduos que foram acometidos por um AVC. Quando se trata de pessoas idosas é necessário atentar para suas particularidades, em virtude de sua faixa etária, a existência de comorbidades, adesão ao tratamento medicamentoso, a reabilitação, condições sociais (familiares e financeiras), entre outras. ${ }^{4}$

Após um episódio de AVC o processo de reabilitação deve transcorrer o mais precoce possível, de preferência ainda no âmbito hospitalar, por meio de assistência da equipe multidisciplinar. Isso para que as sequelas residuais possam ser excluídas ou minimizadas, promovendo o bem-estar e a qualidade de vida do indivíduo, seja no contexto familiar, social e/ou comunitário. ${ }^{5}$ Caso o indivíduo acometido por um AVC tenha permanecido com sequelas, estas poderão levá-lo a um quadro de dependência para a realização das atividades de vida diária. Em idosos com sequelas de AVC, as limitações se exacerbam e contribuem de modo 
significativo para a redução de sua autonomia e independência. Uma vez instalada essa condição, surge a necessidade de um cuidador, que pode ser um familiar (cuidador informal) ou um profissional da saúde (cuidador formal). Em relação à especificidade do cuidar de um familiar, pode aflorar sentimentos ambivalentes com características de satisfação, generosidade, afeto e amor ou de sobrecarga, sofrimento, incerteza e estresse. ${ }^{5}$

Vale destacar que parte da população vítima de AVC apresenta restrição funcional com comprometimento intelectual, cognitivo, motor ou da comunicação, o que pode dificultar a realização das atividades cotidianas, bem como acessar os serviços de saúde. ${ }^{1-2,5}$ Ao fazer uma busca na literatura nacional verificou-se que há poucos estudos que versem sobre o cotidiano de idosos que vivenciaram um AVC.,4-5 Deste modo, ouvir essas pessoas é fundamental para poder compreender como é o viver delas a partir do adoecimento por um AVC. Considerando os aspectos descritos, teve-se como pergunta de pesquisa: como é o viver de idosos após um AVC? Centrado nessa questão esteve o objetivo que foi: compreender o viver de idosos após a ocorrência de um AVC.

\section{Método}

Estudo qualitativo, do tipo descritivo, desenvolvido em um município da região noroeste do Estado do Rio Grande do Sul, vinculado a Estratégias de Saúde da Família (ESF). Participaram da pesquisa idosos vítimas de AVC, e que atenderam aos seguintes critérios de inclusão: idosos (com idade igual ou superior a 60 anos), de ambos os sexos, com diagnóstico de AVC e residentes na área de abrangência das respectivas unidades de saúde. Os idosos que apresentavam déficit de linguagem ou possuíam outra condição clínica, a exemplo de demência, que impossibilitasse a realização da entrevista foram excluídos.

A coleta de dados ocorreu entre janeiro e março de 2018, em três ESF: ESF I, ESF III e ESF IV do município local de estudo. Selecionou-se a ESF I por ser a unidade que concentra o 
5 | Pauli E, Leite MT, Bornholdt L, Hildebrandt LM, Kinalski, SS, Beuter M.

maior número de usuários, com uma média populacional de 4.330 habitantes. Quanto às ESF III e IV, optou-se pelo fato de estarem localizadas em um mesmo espaço físico, abrangendo, respectivamente, uma população de 2.304 e 2.500 usuários, e por concentrarem o maior número de idosos vítimas de AVC do município.

Para localização dos participantes, entrou-se em contato com os Agentes Comunitários de Saúde (ACS), aos quais foi solicitado a relação de idosos vinculados às ESFs de sua área de abrangência, que vivenciaram uma situação de adoecimento por AVC, com condições de comunicação verbal, bem como o endereço dos mesmos. De posse de tais informações, realizouse uma visita ao domicílio de cada idoso, explicando o objetivo da pesquisa e solicitando sua colaboração para participar da mesma. Após o aceite, este assinou, assim como o pesquisador, o Termo de Consentimento Livre e Esclarecido.

Realizou-se entrevista semiestruturada, para a qual utilizou-se formulário com questões relativas a variáveis sociodemográficas: sexo, idade, escolaridade, situação conjugal, condição trabalho, renda, autopercepção de saúde, uso de cigarro, consumo de bebida alcoólica, tipo de AVC, tempo de acometimento do AVC, recidiva, sequelas e ações de lazer. As entrevistas foram gravadas em meio digital e, posteriormente, transcrita na íntegra. Além do instrumento de coleta de dados, realizaram-se anotações pelo pesquisador referentes à comunicação não verbal, como expressões e olhares, identificados durante a entrevista e registrados em diário de campo. A interrupção da coleta de dados ocorreu após o pesquisador verificar que houve saturação das informações. ${ }^{6}$

A análise remete-se às técnicas de pesquisas empregadas para tornar os dados validados e capazes de reproduzir informações sobre determinado contexto ou situação, por meio da produção científica e procedimentos especializados. ${ }^{7}$ Deste modo, seguiu-se os preceitos da análise temática, ${ }^{7}$ que abrange três etapas: pré-análise, na qual houve a retomada dos objetivos da pesquisa, leitura flutuante e constituição do corpus do estudo; exploração do material, 
mediante classificação do texto, com recortes em unidades de registro podendo ser estas, frases, palavras, ideias ou acontecimentos, com o propósito de construir a classificação e agregação dos dados; tratamento e interpretação dos resultados, em que foram propostas inferências e interpretações, relacionando-as com a literatura. Após a análise dos dados, organizaram-se, por convergência de ideias, três categorias: modificações funcionais e sociais na vida de idosos após a ocorrência do AVC; o (des)cuidado após o AVC no entendimento da pessoa idosa; e perspectivas de futuro da pessoa idosa após a ocorrência do AVC.

O projeto de pesquisa foi registrado no Comitê de Ética da Pesquisa institucional CAAE № 80235417.7.0000.5346 e aprovado sob o parecer nº 2.435.518, em 13 de dezembro de 2017. Os relatos foram codificados pela letra E (Entrevistado), seguida de um número conforme a sequência da realização das entrevistas.

\section{Resultados e discussão}

Participaram do estudo 12 idosos, seis do sexo masculino e seis do sexo feminino, com idades entre 60 e 94 anos, média de 72 anos; uma informou não ser alfabetizada, dez possuíam ensino fundamental incompleto e um o ensino médio completo; sete eram casados, três viúvos, um divorciado e um solteiro. Em relação à condição de trabalho, 11 estavam aposentados e um ainda desempenhava atividades no espaço doméstico. Predominaram entrevistados que possuíam renda de um a três salários mínimos, com 10 participantes, enquanto que dois informaram usufruir de três a cinco salários mensais. No que se refere à autopercepção da saúde, seis a avaliaram como boa, quatro ruim e dois como péssima.

Quanto ao tipo do AVC, identificou-se prevalência do isquêmico com nove eventos, um hemorrágico e dois não souberam informar. O tempo do acometimento transcorrido após o AVC variou de cinco meses a oito anos. No que se refere à recidiva, somente um entrevistado informou ter vivenciado mais de um episódio. Nos idosos com sequelas de AVC, em especial 
aqueles com comprometimento motor, identificou-se que os mesmos possuem dificuldade para realizar atividades de lazer; oito idosos informaram não aderir a essa prática, enquanto quatro relataram desenvolver pelo menos uma atividade. Dentre as ações de lazer, as de maior prevalência mencionadas foram: visita a familiares, cultivo de flores, cuidados com o jardim e assistir à televisão.

Posterior à caracterização sociodemográfica, realizou-se leitura das informações, organizando-as, por convergência de ideias, em categorias descritas e discutidas a seguir.

Modificações funcionais e sociais na vida de idosos após a ocorrência do AVC

Ao experenciar um AVC, ocorrem mudanças repentinas na vida dos idosos, tanto do ponto de vista funcional como social, impondo-lhes limitações, com redução da autonomia, independência e sociabilidade, que varia com o grau de comprometimento da doença. Contudo, é possível, em algumas situações, que um indivíduo ao vivenciar um AVC tenha potencial para reabilitar-se funcional e cognitivamente, na perspectiva de retomar a realização de suas atividades básicas e instrumentais da vida diária, sem nenhuma limitação. Nesse sentido, as sequelas que comumente podem permanecer em decorrência da enfermidade são minimizadas, o que pode ser atribuído, em parte, aos avanços tecnológicos no campo da saúde e às diferentes formas de cuidado. Tal entendimento também pode ser identificado nos depoimentos dos idosos participantes deste estudo:

Tem gente que dá um $A V C$, dá um derrame, fica esquecido [...] eu não, eu fiquei normal de tudo. (E12)

Está bem, não sinto nada, está normal. Mudou que agora estou me cuidando. (E4)

No que se refere às incapacidades funcionais, identificou-se que a dificuldade para deambular prevalece. As limitações, que geralmente permanecem, são resultantes do comprometimento de algumas funções corpóreas, em que é comum a presença de mais de uma. 
Estudo $^{8}$ verificou que um idoso com sequelas de AVC apresenta dificuldade em pelo menos três e no máximo cinco funções do corpo, sendo as mais frequentes: dificuldade para deambular, movimentar os braços e perda da memória. Essas incapacidades, por vezes, restringem a saída de seus domicílios devido à presença de barreiras físicas, bem como dificultam a procura dos serviços de saúde. Nessa perspectiva, pode-se inferir que, na presença de limitações, a enfermidade torna-se mais incapacitante, com impacto negativo na vida do indivíduo, pois a paralisia é a função prioritária que o idoso deseja a reabilitação.

Se Deus desse meus passos de novo, minhas pernas para andar, me curasse dessa paralisia, não sei como ia agradecer [chorando]. (E6)

Os idosos que vivenciaram um episódio de AVC possuíam necessidade e desejo de recuperar suas habilidades funcionais para voltar a realizar suas atividades da vida diária (AVD) e, também, para a prática das atividades instrumentais da vida diária (AIVD), as quais eram desempenhadas. Vale destacar que tarefas básicas como autocuidado, mobilidade, alimentar-se, vestir-se, higienizar-se e capacidade de controlar as eliminações vesicais e intestinais se constituem em AVDs. Já as AIVDs são aquelas que permitem a integração de uma pessoa na comunidade, gerir sua casa e a sua vida, como fazer compras, administrar seu dinheiro, utilizar telefone, utilizar transportes. ${ }^{9}$ Estudo que buscou estimar a prevalência da incapacidade funcional e os fatores associados em idosos que sofreram AVC evidenciou que 58,2\% tinham limitações para sair em função de barreiras arquitetônicas e 40,4\% possuíam restrições para acessar os serviços de saúde. ${ }^{10}$ Estudos sugerem uma deterioração das AIVDs com o avançar da idade na presença de doenças crônicas, entre elas as sequelas do AVC.9-10

Não posso trabalhar, isso aí que mudou, não posso fazer nada, mas eu queria fazer, eu tenho muita vontade de trabalhar. (E7)

As modificações funcionais, muitas vezes, são responsáveis por mudanças de hábitos na vida dos idosos com sequelas do AVC. Nessa perspectiva, torna-se necessário que estes 
9 | Pauli E, Leite MT, Bornholdt L, Hildebrandt LM, Kinalski, SS, Beuter M.

busquem novos atalhos no seu dia a dia a fim de atender à demanda das suas AVDs e AIVDs. Além disso, essas limitações obstaculizam a saída de seus domicílios em razão da presença de barreiras físicas, comprometendo, assim, o bem-estar físico e social desses indivíduos. ${ }^{5}$

A restrição funcional requer também modificações no ambiente físico no qual o idoso, após vivenciar a ocorrência de um AVC, passou a utilizar. Isso porque, comumente, eles passaram a necessitar de equipamentos que lhes auxiliem a conduzir sua vida cotidiana. Ainda, com frequência, necessitaram de auxílio de outra pessoa para deslocarem-se na parte interna e externa do domicílio.

A minha casa é muito pequena, apertada, para eu ir no banheiro, não tem como eu entrar de frente, então eu com a cadeira tenho que entrar de ré, me ajeito lá e depois saio de frente. Já não é fácil, precisa de gente para me conduzir nisso aí. (E3)

O vivenciar um AVC deixa lembranças negativas na vida da pessoa que o experienciou. Também, por se tratar de uma condição que demanda recuperação lenta, dificulta o processo de recuperação e reintegração comunitária. ${ }^{11}$ Pesquisa verificou que $27,7 \%$ dos idosos sobreviventes de AVC apresentavam sintomas depressivos. Além disso, nesses pacientes, o grau de dependência funcional se constituiu em fator que favorece a ocorrência de depressão. ${ }^{12}$ Aliado a isto, pode estar relacionado o tempo de recuperação, uma vez que diminui a esperança de reabilitação desses indivíduos.

Alguns entrevistados mencionaram, ainda, receio de uma nova hospitalização, bem como de vivenciar um novo AVC. Esse sentimento se associa às sequelas do AVC, visto que acarretaram limitações funcionais e os tornaram dependentes de cuidados contínuos. Nessa perspectiva, realizavam os cuidados necessários para que não ocorra um novo episódio.

Eu fiquei com medo de voltar ao hospital, estava enjoada do hospital, vim para casa, vou ter que consultar estou me afogando. (E10) 
Tenho medo, por isso que me cuido, me cuido para não me dar mais, e sempre estou fazendo exame, todo mês eu faço exame. (E4)

Presume-se que quanto maior o conhecimento relacionado aos fatores de risco modificáveis do AVC, mais sensível será a prática do indivíduo para o autocuidado. Tais informações subsidiam mudanças no estilo de vida, principalmente no que diz respeito à alimentação saudável, prática de exercícios físicos regulares, tabagismo, etilismo e cuidados primordiais na prevenção dessa doença cerebrovascular. ${ }^{13}$ Ainda, ressalta-se a importância da adesão a essas recomendações, bem como a realização de consultas periódicas, com vistas à prevenção de um evento inicial, assim como a recidiva do AVC, agravo responsável por elevados índices de sequelas e mortalidade.

No que tange às incapacidades funcionais, foi possível identificar, no depoimento de um participante que vivenciou um AVC, limitações em sua vida sexual, função esta comumente comprometida pela enfermidade e responsável por contribuir para a redução da sociabilidade e integração do indivíduo na sociedade. No que se refere às sequelas do AVC, percebeu-se que, muitas vezes, a função sexual não é considerada pela equipe de saúde e pelos próprios idosos como uma limitação funcional que pode comprometer o bem-estar físico e emocional desse indivíduo.

Para dizer bem a verdade faz quatro anos que eu não faço sexo. Todo homem precisa de sexo. Isso aí mudou bastante. Tomo muito remédio e eu acho que é o remédio que está me prejudicando. (E11)

Estudo que buscou avaliar a função sexual após o AVC em indivíduos maiores de 18 anos verificou que, aproximadamente, a metade deles permaneceu sexualmente ativo após vivenciar a doença. Estes, em sua totalidade, percebiam sua saúde como boa, ao contrário dos que não tinham mais vida sexual ativa. ${ }^{14}$ É comum que indivíduos com sequelas do AVC vivenciem quase que em sua totalidade modificações funcionais e sociais. Considera-se que as incapacidades 
11 | Pauli E, Leite MT, Bornholdt L, Hildebrandt LM, Kinalski, SS, Beuter M.

funcionais são determinantes nas relações sociais dos indivíduos e comprometem o cotidiano dos mesmos.

Mudou tudo, minha vida na verdade eu sou mesmo considerado presidiário, porque tudo tem que me dar, tem que me alcançar. Então, é mesmo que eu estar atrás de uma grade, se precisar de uma coisa tem que me trazer. (E3)

O comprometimento do cotidiano pode ser atribuído principalmente pelas dificuldades nas relações familiares, evidenciada pela diminuição da capacidade para a realização das AVDs, de trabalho e sociais, visto que muitas vezes o indivíduo fica impedido de retornar ao trabalho e às suas atividades sociais. ${ }^{15}$ Em relação ao modo como ocorreu o AVC, identificou-se que esta é uma condição que acontece de forma súbita, com potencial para causar disfunções emocionais, resultando em mudanças negativas na vida das pessoas. Porém, geralmente os indivíduos desconhecem as causas que levaram à ocorrência da enfermidade.

Eu estava bem, anoiteci bom e acordei assim, foi repentino. (E5)

Eu para te dizer a verdade porque que me deu não sei. (E12)

Diante dessa condição, faz-se necessária a assistência multidisciplinar ao idoso vítima de AVC como forma de prestar cuidado que contemple os aspectos físicos e emocionais, tendo em vista o processo de reabilitação e reintegração comunitária. Nesse sentido, torna-se fundamental que os serviços de saúde estejam habilitados para o acompanhamento do idoso que vivenciou um AVC, por meio de assistência qualificada, holística e integral. Além disso, a assistência conjunta da rede de saúde possibilita ao cuidador suporte emocional, proporcionando maior bem-estar ao familiar, o que contribui para a recuperação.

\section{$O$ (des)cuidado após o $A$ VC no entendimento da pessoa idosa}

O idoso com AVC requer assistência contínua na ESF e no domicílio, de tal modo que possa favorecer sua reabilitação cognitiva, funcional e emocional ou minimizar as sequelas instaladas. O despreparo para o cuidar causa na família instabilidade emocional, além de 
comprometer a reabilitação e o bem-estar do indivíduo com sequelas do AVC. Essa condição, evidenciada pelo desconhecimento do familiar frente à linha de cuidado, pode ser atribuída à ausência de orientação dos profissionais, ainda na instituição hospitalar, bem como ao não envolvimento da equipe de saúde da atenção primária no processo de cuidar de um idoso.

Com o intuito de minimizar as sequelas advindas do AVC, torna-se imprescindível a assistência médico-hospitalar imediata, com escuta qualificada e de conduta efetiva. No entanto, verificou-se, por meio de um relato, que ao procurar o atendimento o participante não teve suas queixas valorizadas, fato que pode ter agravado o quadro clínico em virtude da falta de suprimento sanguíneo na área em que houve a lesão. Desse modo, pode-se identificar certa negligência profissional no modo de prestar atendimento, constituindo-se em um descuidado:

Não precisava ter me dado esse derrame, eu estava com dor de cabeça e me sentindo mal, chegamos lá pediram para apertar a mão dele [do médico] $e$ eu não consegui. Ele disse que eu estava me fazendo, que queria aparecer, chamar a atenção. Vim para casa, passei mal, daí bem cedinho, minha filha me levou no hospital de novo, aquele médico já tinha saído de lá, tinha outro doutor [...] ele disse 'a senhora tem um AVC', na hora ele viu!(E10)

Estudo que buscou compreender a vida de pessoas após o acidente vascular cerebral verificou que quase a totalidade dos indivíduos envolvidos no cuidado do idoso desconhece as causas e a sintomatologia de um AVC, assim como a forma de prestar assistência a esse indivíduo. Além disso, cuidados com lesões por pressão e orientações após a ocorrência desta doença foram negados pelos cuidadores nessa mesma proporção. ${ }^{16}$ Ressalta-se que essas informações são primordiais no cuidado ao indivíduo e que deveriam ser de conhecimento dos cuidadores, de modo a qualificar a assistência a quem dela necessita, os quais, muitas vezes, encontram-se fragilizados em seus domicílios.

Um indivíduo ao procurar atendimento referindo sinais e sintomas característicos de AVC, tais como cefaleia, crises convulsivas, afasia, hemiparesia e desvio de comissura labial, encontra fragilidades no serviço relativo ao tempo de atendimento e à falta de qualificação 
pessoal em prestar a assistência. ${ }^{16}$ Ainda, no que diz respeito à transição do cuidado após a alta hospitalar, a maioria das pessoas acometidas pelo AVC e sua família/cuidador continuam necessitando de acompanhamento e cuidados especiais individualizados. Para que haja prosseguimento dos cuidados principiados no espaço hospitalar, se faz necessário que os envolvidos recebam orientações de acordo com as demandas e limitações oriundas da doença. ${ }^{17}$ Embora haja disponibilidade familiar para a prestação do cuidado, pode-se identificar um descuidado por parte do serviço de saúde:

Nenhuma orientação, mas e agora como eu vou fazer? Daí meu irmão disse, não! Eu cuido de ti. Até a namorada não quis, caiu fora. (E5)

Os idosos participantes deste estudo apontaram como ponto positivo o envolvimento familiar no processo de cuidar e de reabilitação de sua condição clínica. Nesse sentido, presume-se que a presença do familiar cuidador tem duplo impacto na vida da pessoa idosa que foi vítima de um AVC. Ela tem papel fundamental para a realização do cuidado necessário e, também, constitui-se em um elemento de suporte emocional e afetivo. Porém, essa tarefa tem sido desenvolvida de modo solitário, sem a ajuda dos serviços de saúde.

Para que os serviços de saúde também ofereçam cuidado com qualidade, é necessário que eles incluam a atenção à família. Isso porque a família se constitui no elo de acesso do idoso, vítima de AVC, aos serviços de saúde e, também, é ela que vai garantir a manutenção da assistência. ${ }^{18}$ Assim sendo, os serviços de saúde podem fornecer apoio aos cuidadores familiares e interagir com a família-paciente, considerando as peculiaridades de cada situação e as identidades dos indivíduos envolvidos, tornando a família sujeito do cuidado:

Fiquei muito bem. Foi um caminho melhor para mim porque meus filhos estavam se importando e correndo por mim. (E4)

Ela me cuida bem e tem paciência comigo.(E1) 
No estudo realizado com o objetivo de compreender os significados da experiência da enfermidade na perspectiva de sobreviventes de AVC, os autores verificaram que o envolvimento familiar, como determinante na reabilitação do indivíduo vítima do AVC, ocorreu por meio do diálogo, passeios, convívio com os amigos, relações que permitiram ampliar o vínculo e o afeto entre os envolvidos e, consequentemente, foram benéficas no que diz respeito ao quadro clínico e emocional do mesmo. ${ }^{18} \mathrm{Em}$ contrapartida, percebe-se que o contexto familiar é distinto e, portanto, pode haver situações em que, habitualmente, há ausência do apoio familiar junto ao idoso com sequelas do AVC. Nessa perspectiva, denota-se a partir do relato de uma entrevistada o quanto poderia ser favorável a presença de um familiar na sua reabilitação. Essa condição pode ser considerada, também, como um (des)cuidado por parte do familiar:

Acho que não ligam [chorando], nem sabem que tem mãe, acho que um filho deveria dar mais atenção, mais amor, pela mãe. Eu queria que me puxasse mais para mim caminhar, para ver se eu conseguia caminhar. (E6)

Além disso, a ausência de alguns familiares, por vezes, resulta em abandonos afetivos e/ou em sobrecarga do familiar prestador de cuidados, uma vez que não ocorre a divisão das responsabilidades entre seus membros. Nesse sentido, pode haver comprometimento da assistência prestada a vítima do AVC, o que implica na reabilitação ou não desse indivíduo, assim como haver presença de conflitos entre os membros da família. Diante da continuidade do cuidado, é importante que após a alta hospitalar a assistência seja conduzida pela atenção básica à saúde com o envolvimento familiar. ${ }^{17}$

Perante a ocorrência de um AVC, os indivíduos envolvidos, vítima e familiares, passam por mudanças, pois rotineiramente há presença de sequelas e incapacidades em detrimento da autonomia e independência que havia anteriormente. Nesse sentido, emergiram sentimentos relacionados à sua dependência de um cuidador para a realização de atividades básicas da vida diária. Essa condição, embora não seja a que eles desejavam, é percebida e aceita com certa tranquilidade pelos idosos entrevistados: 
15 | Pauli E, Leite MT, Bornholdt L, Hildebrandt LM, Kinalski, SS, Beuter M.

Tivesse outra pessoa para me cuidar, mais pessoas, eles eram mais livres. Eles querem sair e não podem por causa de mim, mas eu quero que eles saem, sair para passear, eles têm a vida deles. (E7)

Como mencionado pelo E7, há descontentamento do indivíduo com sequelas de AVC, especialmente em função de que requer a presença de um cuidador e ele identifica que o lazer de seus familiares fica prejudicado, comprometido pela sua necessidade de cuidado, pois vivenciou a enfermidade e carece de cuidados para a realização de atividades rotineira. ${ }^{18}$ Diante de uma condição debilitante, um participante relembrou da independência que possuía anteriormente na realização das AVD e AIVD, enquanto outro expressou sua vontade de superar, na tentativa de ser independente, mesmo com sequelas incapacitantes:

Ah claro, que eu não gostaria de estar exigindo pedindo tal coisa isso e aquilo porque eu nunca fui acostumado a pedir nada, fui acostumado a ajudar não ser ajudado. (E3)

Eu tomo banho sozinho, estou me habituando a fazer tenho que fazer, não depender de outras pessoas, procurar me superar. Eu tenho essas pessoas que cuidam de mim, mas eu procuro fazer o que estiver ao meu alcance. (E5)

Nessa mesma perspectiva, ${ }^{19}$ o indivíduo vítima de AVC percebe a doença e sua condição atual como forma de buscar a superação na tentativa de almejar sua reabilitação. Além disso, torna-se necessário o apoio da família perante essa condição como forma de incentivo e suporte ao idoso incapacitado. O tripé da assistência ao idoso após o AVC constitui-se na equipe de saúde, na família e nos próprios idosos. À equipe de saúde cabe desenvolver a assistência imediata e resolutiva na instituição hospitalar e o acompanhamento desse indivíduo no domicílio pela equipe da ESF. A família precisa estar preparada para prestar o cuidado do indivíduo vítima de AVC, bem como fornecer suporte para o enfrentamento da doença e possibilitar a reabilitação. E quanto maior o desejo do idoso em reabilitar-se, maior será a sua chance de recuperação. 


\section{Perspectivas de futuro da pessoa idosa após a ocorrência do AVC}

A ocorrência de um AVC impacta negativamente na vida de um indivíduo e de sua família. Essa condição parece dificultar mais o processo de reabilitação quando se trata de uma pessoa idosa, que pode favorecer para sua desestabilização emocional, podendo levá-lo a aceitar a nova condição que lhe é imposta, em termos de limitações físicas. Em contrapartida, é possível observar que há atitudes de superação na busca por maior qualidade de vida. Assim, observou-se que cada indivíduo que possui uma doença crônica e incapacitante reage de forma distinta e inesperada, o que determina a necessidade do cuidado na perspectiva do idoso que vivenciou um AVC.

Nesse contexto, o idoso, vítima de AVC, com expectativas positivas acerca de sua reabilitação, tem nelas um ponto determinante para a recuperação da sua condição de saúde e da sua autonomia e independência. Também, é necessária a presença da família e dos serviços de saúde como incentivadores. Com relação à necessidade de cuidado, presume-se que a demanda assistencial é maior naqueles que possuíam boas expectativas, quando comparados aos que não tinham, estes aceitavam de forma passiva a enfermidade:

Estou em plena recuperação. Como eu tenho que usar o lado esquerdo eu ainda não posso escrever, não posso assinar o nome, mas eu já consigo comer com a mão esquerda, se tenho que fazer uma comida, esquento com a mão esquerda, então eu procuro me superar entende? A gente acha que não pode fazer, mas tentando, nem que seja quantas vezes for preciso, tu consegue. (E5)

Foi possível, ainda, observar um período de transição entre o acometimento da enfermidade até a retomada de sua capacidade funcional e/ou cognitiva. Trata-se de um processo de reabilitação lento e faz-se necessário que os idosos estejam conscientes desse processo para maior engajamento perante a sua recuperação:

Olha, eu pretendo ainda melhorar. Tudo é uma questão de tempo, é uma recuperação lenta, não é assim do dia para a noite que se recupera, que nem gripe, tu gripado hoje e amanhã já está bom. (E5) 
17 | Pauli E, Leite MT, Bornholdt L, Hildebrandt LM, Kinalski, SS, Beuter M.

Mesmo que alguns entrevistados tenham manifestado boas perspectivas de recuperação futuras, prevaleceram expressões de tristeza e incertezas após vivenciar o AVC. Tais sentimentos contribuem para a aceitação da doença e suas complicações, dificultando a reabilitação desses indivíduos. O sofrimento após o AVC pode resultar no desenvolvimento de episódios depressivos que, por vezes, fizeram os idosos expressarem que a morte é uma perspectiva de quadro evolutivo da doença:

Para dizer bem a verdade acho que já vivi bastante, se acontecer de me dar outro derrame já está na hora de ir. Já estou com 74 anos, como diz o ditado acho que já está na hora de viajar. (E11)

Ressalta-se que, geralmente, trata-se de uma recuperação em longo prazo pela complexidade da reabilitação das funções corpóreas. Diante dessa condição, faz-se necessária assistência multidisciplinar e holística de modo que o cuidado esteja voltado aos aspectos físicos e mentais do indivíduo vítima de AVC.

Frente a ocorrência de um AVC, a pessoa idosa tem que se adaptar às limitações e às condições que emergem, sendo necessário ajustar as vivências individuais, e aprender a viver com a enfermidade e/ou sequelas. ${ }^{20}$ Além disso, ao se deparar com uma doença crônica, sentimentos como medo, preocupação e aflição são inseridas no cotidiano do idoso e sua família. Estas situações podem ocorrer pela dificuldade da limitação que a doença proporciona, favorecendo a fragilização e requerendo a necessidade de adequação a nova condição. Além disso, denota-se que as incapacidades contribuem para o deficit do autocuidado, fazendo-se necessário o acompanhamento qualificado, bem como adaptações no domicílio, como forma de minimizar os agravantes e proporcionar maior autonomia e independência ao mesmo. 


\section{Considerações finais}

Esta pesquisa permitiu evidenciar que, após a ocorrência de um AVC, emergiram mudanças repentinas no cotidiano de vida dos idosos, o que, por vezes, causou-lhes limitações. Tais restrições caracterizaram-se por diferentes graus de comprometimentos, físicos e psíquicos, resultando em alterações no bem-estar e na sociabilidade da pessoa idosa.

As incapacidades apresentadas pela pessoa idosa, vítima de AVC, podem resultar em comprometimento emocional, físico e psíquico, impactando também nas relações sociais. A dificuldade em deambular teve destaque, com desejo dos idosos em reabilitar-se para retomar suas habilidades funcionais. Destaca-se que, por vezes, a recuperação dessas funções não ocorreu ou se deu de forma parcial, levando os idosos que vivenciaram um AVC a buscar formas alternativas para atender as suas necessidades de vida diária, como realizar mudanças no ambiente domiciliar e ter a presença de cuidadores.

Houve menção relativa ao receio por parte dos idosos em vivenciar novos episódios de AVC, hospitalizações e limitações. Como forma de prevenção de eventos futuros, eles destacaram cuidados com a alimentação saudável, prática de exercícios físicos, abandono do tabagismo e etilismo e a realização de consultas periódicas.

Quanto aos aspectos do cuidado, foi possível identificar que há potencialidades e fragilidades no que se refere à assistência à saúde desses indivíduos, seja ela no âmbito hospitalar, familiar ou da atenção primária à saúde. A família deve ser e estar preparada para apoiar o idoso, auxiliando-o em suas incapacidades e incentivando-o a buscar a recuperação.

Considera-se que este estudo possui como limitação o fato de ter sido realizado em uma única realidade, com participação de idosos, condição que impossibilita sua generalização. Desse modo, sugere-se a realização de novas investigações, as quais possam ampliar o território 
19 | Pauli E, Leite MT, Bornholdt L, Hildebrandt LM, Kinalski, SS, Beuter M.

e, também, os participantes, em que outros atores envolvidos no cuidado de idosos que vivenciaram um ou mais episódios de AVC possam ser incluídos.

Entende-se que esses resultados possam ser utilizados por membros da equipe de saúde, incluindo a enfermagem, e familiares de idosos que vivenciaram um ou mais episódios de AVC como forma de qualificar o cuidado ofertado a esses indivíduos. Nesse contexto, os resultados podem contribuir para a prática de enfermagem, uma vez que fornecem informações importantes que possibilitam balizar ações de cuidado aos idosos vítimas de AVC e seus familiares. Além disso, objetiva-se que gestores e profissionais de saúde possam ter um olhar voltado à promoção da saúde e prevenção do AVC com o objetivo de reduzir os índices de morbimortalidade por esta enfermidade, especialmente entre idosos.

\section{Referências}

1. Souza IMB, Moraes WSLA, Silva LA, Pereira RMO, Alves EG. Prevalência de acidente vascular cerebral em idosos internados no Hospital Regional no município de Coari, Amazonas. EFDeportes.com [Internet]. 2015 [acesso em 2018 out 18];20(207). Disponível em: https://www.efdeportes.com/efd207/prevalencia-de-acidente-vascular-cerebral-em-idosos.htm

2. Ministério da Saúde (BR), Secretaria de Atenção à Saúde, Departamento de Ações Programáticas Estratégicas. Diretrizes de atenção à reabilitação da pessoa com acidente vascular cerebral. Brasília (DF): Ministério da Saúde; 2013. 72 p.

3. Platz T. Evidence-based guidelines and clinical pathways in stroke rehabilitation - an international perspective. Front Neurol [Internet]. 2019 [acesso em 2020 fev 13];10. Disponível em: https://www.frontiersin.org/articles/10.3389/fneur.2019.00200/full

4. Silva MCL, Polese JC, Starling JMP, Pereira LSM. Caracterização clínica e motora-funcional de idosos hospitalizados pós-Acidente Vascular Cerebral. Rev Neurociênc [Internet]. 2014 [acesso em 2018 out 18];22(3):337-43. Disponível em: https://periodicos.unifesp.br/index.php/neurociencias/article/view/8069

5. Reis RD, Pereira EC, Pereira MIM, Soane AMNC, Silva JV. Significados, para os familiares, de conviver com um idoso com sequelas de Acidente Vascular Cerebral (AVC). Interface (Botucatu) [Internet]. 2017 [acesso em 2018 out 13];21(62):641-50. Disponível em: https://www.scielosp.org/pdf/icse/2017.v21n62/641-650

6. Minayo MCS. Amostragem e saturação em pesquisa qualitativa: consensos e controvérsias. Rev Pesqui 
O viver de idosos após o acidente vascular cerebral $\mid 20$

Qual [Internet]. 2017 [acesso em 2020 fev 13];5(7):1-12. Disponível em: https://editora.sepq.org.br/index.php/rpq/article/view/82/59

7. Minayo MCS, Deslandes SF. Pesquisa social: teoria, método e criatividade. Petrópolis (RJ): Vozes; 2013.

8. Carmo JF, Oliveira ERA, Morelato RL. Incapacidade funcional e fatores associados em idosos após o Acidente Vascular Cerebral em Vitória - ES, Brasil. Rev Bras Geriatr Gerontol [Internet]. 2016 [acesso em 2018 out 18];19(5):809-18. Disponível em: http://www.scielo.br/scielo.php?pid=S180998232016000500809\&script=sci_arttext\&tlng=pt

9. Carmona-Torres JM, Rodríguez-Borrego MA, Laredo-Aguilera JA, López-Soto PJ, Santacruz-Salas E, Cobo-Cuenca AI. Disability for basic and instrumental activities of daily living in older individuals. PLoS ONE [Internet]. 2019 [acesso em 2020 fev 15];14(7):e0220157. Disponível em: https://doi.org/10.1371/journal.pone.0220157

10. Mueller-Schotte S, Zuithoff NPA, Schouw YTV, Schuurmans MJ, Bleijenberg N. Trends in risk of limitations in instrumental activities of daily living over age in older persons with and without multiple chronic conditions. J Gerontol A Biol Sci Med Sci [Internet]. 2020 [acesso em 2020 fev 13];75(1):197-203. Disponível em: https://doi.org/10.1093/gerona/glz049

11. Santos AM, Vila VSC, Ribeiro MFM, Souza ACS. Experiência da enfermidade de idosos após o acidente vascular cerebral. 50 Congresso Ibero-Americano em Investigação Qualitativa - CIAIQ 2016; 2016 jul 12-14; Porto (Portugal). Atas. (Atas CIAIQ 2016 [Internet]. 2016 [acesso em 2020 fev 13];2(1):13209). Disponível em: https://proceedings.ciaiq.org/index.php/ciaiq2016/article/view/889

12. Santos EB, Rodrigues RAP, Pontes-Neto OM. Prevalência e preditores de depressão pós-AVC em idosos sobreviventes de acidente vascular cerebral. Arq Neuro Psiquiatr [Internet]. 2016 [acesso $2020 \mathrm{fev}$ 13];74(8):621-5. Disponível em: http://www.scielo.br/scielo.php?pid=S0004282X2016000800621\&script=sci_abstract\&tlng=pt

13. Lima MJMR, Moreira TMM, Florêncio RS, Braga Neto P. Fatores associados ao conhecimento dos adultos jovens sobre histórico familiar de Acidente Vascular Cerebral. Rev Latinoam Enferm [Internet]. 2016 [acesso em 2018 out 18];24:e2814. Disponível em: http://www.scielo.br/pdf/rlae/v24/pt_0104-1169rlae-24-02814.pdf

14. Pereira ARR, Dantas DS, Torres VB, Viana ESR, Correia GN, Magalhães AG. Associação entre função sexual, independência funcional e qualidade de vida em pacientes após acidente vascular encefálico. Fisioter Pesqui [Internet]. 2017 [acesso em 2018 set 20];24(1):55-61. Disponível em: http://www.periodicos.usp.br/fpusp/article/view/ 132811/

15. Canuto MAO, Nogueira LT, Araujo TME. Qualidade de vida relacionada com a saúde de pessoas após Acidente Vascular Cerebral. Acta Paul Enferm [Internet]. 2016 [acesso em 2018 set 20];29(3): 245-52. Disponível em: http://www.scielo.br/pdf/ape/v29n3/1982-0194-ape-29-03-0245.pdf 
16. Silva IFG, Neves CFS, Vilela ACG, Bastos LMD, Henriques MILS. Viver e cuidar após o Acidente Vascular Cerebral. Referência [Internet]. 2016 [acesso em 2018 dez 20];4(8):103-11. Disponível em: http://www.scielo.mec.pt/pdf/ref/vserIVn8/serIVn8a12.pdf

17. Saldan GG, Figueiredo FSF, Misawa F, Rego AS, Salci MA, Radovanovic CAT. Construction of educational technology for home care after encephalic vascular accident: case report. Rev Enferm UFPE On Line [Internet]; 2017 [acesso em 2020 fev 19];11(4):1784-93. Disponível em: https://periodicos.ufpe.br/revistas/revistaenfermagem/article/view/15251

18. Silva JK, Vila VSC, Ribeiro MFM, Vandenberghe L. Survivors' perspective of life after stroke. Rev Eletrônica Enferm [Internet]. 2016 [acesso em 2018 set 20];18:1-10. Disponível em: https://revistas.ufg.br/fen/article/view/34620

19. Lopes MCL, Santos AL, Marcon SS. Convivência familiar com a dependência decorrente do acidente vascular encefálico em hipertensos. Semina Cienc Biol Saude [Internet]. 2014 [acesso em $2018 \mathrm{dez}$ 02];35(1):75-86. Disponível em: http:/www.uel.br/revistas/uel/index.php/seminabio/ article/view/15429/15806

20. Girondi JBR, Schier J, Hammerschimid KSA, Bento RR, Souza LP, Sebold LF. Enfrentando e ressignificando o Acidente Vascular Cerebral: percepção de idosos atendidos na rede de atenção à saúde. Rev Kairós [Internet]. 2016 [acesso em 2020 fev 13];19(1):317-38. Disponível em: https://revistas.pucsp.br/index.php/kairos/article/view/35586

\section{Autor correspondente}

Marinês Tambara Leite

E-mail: tambaraleite@yahoo.com.br

Endreço: Rua Floriano Peixoto, 776 - Centro -- Ijuí-RS

CEP: 98700-000

\section{Contribuições de Autoria}

1 - Eglon Pauli

Contribuições na concepção do estudo; coleta, análise, interpretação e discussão dos dados; elaboração do manuscrito com revisão crítica e aprovação final da versão a ser publicada.

\section{2 - Marinês Tambara Leite}

Contribuições substanciais, coordenação, na concepção do estudo; análise, interpretação e discussão dos dados; elaboração do manuscrito com revisão crítica e aprovação final da versão a ser publicada.

\section{3 - Larissa Bornholdt}

Contribuições na análise, interpretação e discussão dos dados; elaboração do manuscrito com revisão crítica e aprovação final da versão a ser publicada. 


\section{4 - Leila Mariza Hildebrandt}

Contribuições na elaboração do manuscrito com revisão crítica e aprovação final da versão a ser publicada.

\section{5 - Sandra da Silva Kinalski}

Contribuições na elaboração do manuscrito com revisão crítica e aprovação final da versão a ser publicada.

\section{6 - Margrid Beuter}

Contribuições na elaboração do manuscrito com revisão crítica e aprovação final da versão a ser publicada.

\section{Como citar este artigo}

Pauli E, Leite MT, Bornholdt L, Hildebrandt LM, Kinalski, SS, Beuter M. O viver de idosos após o acidente vascular cerebral. Rev. Enferm. UFSM. 2020 [Acesso em: Anos Mês Dia]; vol.10 e29: 1-22. DOI:https://doi.org/10.5902/2179769239070 